\title{
Barriers and Delays in Tuberculosis Diagnosis and Treatment Services: Does Gender Matter?
}

\author{
Wei-Teng Yang, ${ }^{1}$ Celine R. Gounder, ${ }^{2}$ Tokunbo Akande, ${ }^{1}$ Jan-Walter De Neve, ${ }^{3}$ \\ Katherine N. McIntire, ${ }^{2}$ Aditya Chandrasekhar, ${ }^{1}$ Alan de Lima Pereira, ${ }^{1}$ Naveen Gummadi, ${ }^{4}$ \\ Santanu Samanta, ${ }^{5}$ and Amita Gupta ${ }^{1,2,6}$ \\ ${ }^{1}$ Johns Hopkins Bloomberg School of Public Health, Baltimore, MD 21205, USA \\ ${ }^{2}$ Department of Medicine, Johns Hopkins University School of Medicine, Baltimore, MD 21287, USA \\ ${ }^{3}$ Harvard School of Public Health, Boston, MA 02115, USA \\ ${ }^{4}$ Narayana Hrudayalaya Hospital, Hyderabad 500055, India \\ ${ }^{5}$ All India Institute of Medical Sciences, New Delhi 110029, India \\ ${ }^{6}$ Center for Clinical Global Health Education, 600 North Wolfe Street, Phipps 540B, Baltimore, MD 21287, USA
}

Correspondence should be addressed to Amita Gupta; agupta25@jhmi.edu

Received 12 January 2014; Accepted 7 April 2014; Published 28 April 2014

Academic Editor: Edward A. Graviss

Copyright (C) 2014 Wei-Teng Yang et al. This is an open access article distributed under the Creative Commons Attribution License, which permits unrestricted use, distribution, and reproduction in any medium, provided the original work is properly cited.

\begin{abstract}
Background. Tuberculosis (TB) remains a global public health problem with known gender-related disparities. We reviewed the quantitative evidence for gender-related differences in accessing TB services from symptom onset to treatment initiation. Methods. Following a systematic review process, we: searched 12 electronic databases; included quantitative studies assessing gender differences in accessing TB diagnostic and treatment services; abstracted data; and assessed study validity. We defined barriers and delays at the individual and provider/system levels using a conceptual framework of the TB care continuum and examined genderrelated differences. Results. Among 13,448 articles, 137 were included: many assessed individual-level barriers (52\%) and delays (42\%), 76\% surveyed persons presenting for care with diagnosed or suspected TB, $24 \%$ surveyed community members, and twothirds were from African and Asian regions. Many studies reported no gender differences. Among studies reporting disparities, women faced greater barriers (financial: $64 \%$ versus $36 \%$; physical: $100 \%$ versus $0 \%$; stigma: $85 \%$ versus $15 \%$; health literacy: $67 \%$ versus $33 \%$; and provider-/system-level: $100 \%$ versus $0 \%$ ) and longer delays (presentation to diagnosis: $45 \%$ versus $0 \%$ ) than men. Conclusions. Many studies found no quantitative gender-related differences in barriers and delays limiting access to TB services. When differences were identified, women experienced greater barriers and longer delays than men.
\end{abstract}

\section{Introduction}

Tuberculosis (TB) remains a significant global public health issue. Significantly, the TB disease burden is unequally distributed among men and women. Of the estimated 8.7 million incident $\mathrm{TB}$ cases and 1.4 million deaths caused by TB globally in 2011, roughly one-third occurred among women (2.9 million incident TB cases and 0.5 million deaths) [1]. Currently, it is unclear whether these disparities are due to sex-related differences (i.e., biology), gender-based differences (i.e., sociocultural practices and different social roles of men and women), or both [2-4]. Until recently, gender-related differences in the epidemiology, diagnosis, treatment, outcomes, and socioeconomic costs of TB have received relatively little attention. To address this knowledge gap, the World Health Organization (WHO) has proposed a framework and priorities for research on gender and TB [5].

To date, gender-based research supports that men and women respond differently to illness and face different barriers when accessing TB diagnostic and treatment services [2]. Barriers that limit access to TB services occur at the individual and provider/system levels. Individual-level barriers involve physical (distance to TB services and access to transport), financial (the direct and indirect costs of seeking TB services), stigma (stigma surrounding TB and its association with HIV), health literacy (TB-related knowledge 
and education), and sociocultural (gender roles and status in the family) factors, whereas provider/system-level barriers include provider degree of suspicion for $\mathrm{TB}$, the number and types of providers seen before $\mathrm{TB}$ diagnosis, provider adherence to national TB program guidelines, and patient satisfaction with TB services. A comprehensive understanding of gender-related differences in barriers and delays at each level is needed so that researchers and policymakers can formulate and prioritize gender-specific interventions to improve the global impact of TB services.

Although several reviews have examined gender-related barriers and delays in seeking TB care [2, 3, 6-11], none have simultaneously assessed the contribution of both barriers and delays in a systematic manner. Furthermore, previous reviews have assessed a narrow study population. Currently, no review has captured the full continuum of TB care by including studies that have surveyed the general population, highrisk populations (e.g., homeless or HIV-infected persons), TB suspects who may not have sought care (e.g., untreated individuals with chest symptoms in the community), and TB patients and suspects presenting for care.

Our review aims to address these limitations. Using a partially-adopted, published framework [5], we systematically reviewed the literature to examine the quantitative evidence for gender-related differences in the barriers and delays that limit access to TB services along the continuum of care from symptom onset to treatment initiation. In this report, we present the findings from our quantitative review, which have important implications for TB service programs, research, and policymakers alike.

\section{Methods}

\subsection{Systematic Review Process}

2.1.1. Search Strategy. We searched 12 electronic databases for human and English articles published between January 1953 and October 2010. We developed our search strategy for MEDLINE using PubMed with a combination of controlled vocabulary and keyword terms and phrases (see Supplementary Material available online at http://dx.doi.org/10.1155/2014/461935). The strategy was then translated for the Excerpta Medica Database (EMBASE), the Cumulative Index to Nursing and Allied Health Literature (CINAHL), Global Health, Popline, Africa Wide, LILACS, Web of Science, and the inclusive databases of the Cochrane Library using their respective thesaurus terms, synonyms, and keywords. Citations from each database were imported into a reference management system, and duplicates were removed.

2.1.2. Study Selection Criteria. We included quantitative studies that reported on gender-related differences in barriers to and/or delays in accessing TB diagnostic and treatment services and studied human participants aged 15 years or older. Studies that did not provide a gender comparison as well as case reports, editorials, review articles, commentaries, practice guidelines, and studies of treatment compliance and/or outcomes were excluded. Participants were defined as persons with diagnosed or suspected TB, persons from either the general population or high-risk populations (e.g., HIV-infected, homeless, and prisoner), or health care providers. Diagnosed TB included both pulmonary and extrapulmonary forms, and $\mathrm{TB}$ diagnosis could be made by sputum smear microscopy, culture, or chest X-ray using histopathological or clinical criteria.

2.1.3. Study Selection Process. Following deduplication, studies were reviewed sequentially by title, abstract, and in fulltext form (Figure 1). At each stage, two reviewers independently evaluated each study against study selection criteria. Articles were included or excluded only when both reviewers were in agreement, and conflicts were resolved by a third, independent reviewer (AC, AG, or CRG). To ensure sufficient concordance between reviewers, a pilot review and reviewer discussion were conducted at each stage before proceeding with the remaining studies. Six reviewers conducted the title screen (ADP, JWDN, NG, SS, TA, and WTY), and four reviewers conducted the abstract screen and the fulltext screen (ADP, JWDN, TA, and WTY). Following the full-text screen, included articles underwent the full-text assessment, which included data abstraction and a study validity assessment.

2.1.4. Data Abstraction. Four reviewers (ADP, JWDN, TA, and WTY) independently abstracted quantitative data from each included full-text article in duplicate, and any conflicts were resolved through discussion with a third, independent reviewer (AG or CRG). Abstracted summary measures included differences in means or proportions, risk ratios, odds ratios, and hazards ratios.

2.1.5. Validity Assessment. We used validity assessment tools to examine the quality of studies that inform our review; the assessment was not used to exclude studies. We assessed observational studies using items adopted from the methods and results sections of the Strengthening the Reporting of Observational Studies in Epidemiology (STROBE) checklist [148]. We used items adopted from the Consolidated Standards of Reporting Trials (CONSORT) checklist extension for clustered randomized trials to assess an included clustered randomized trial [149] and a pragmatic randomized controlled trial [150]. Two reviewers independently assessed the validity of each study using the adopted items (TA and WTY), and conflicts were resolved through discussion and arbitration with a third reviewer (CRG).

2.2. Outcomes and Definitions. Outcomes were quantitative associations between gender and both barriers and delays that limit access to TB services along the full continuum of TB care from symptom onset through diagnosis and treatment initiation. Figure 2 presents the conceptual framework that we used to define barriers and delays at the individual and provider/system levels at various time points along the continuum of TB care. Individual-level barriers were defined to be financial (the direct or indirect costs of TB care, including costs of travel, diagnosis, and/or treatment as well as the opportunity costs of lost employment, compensation, or 


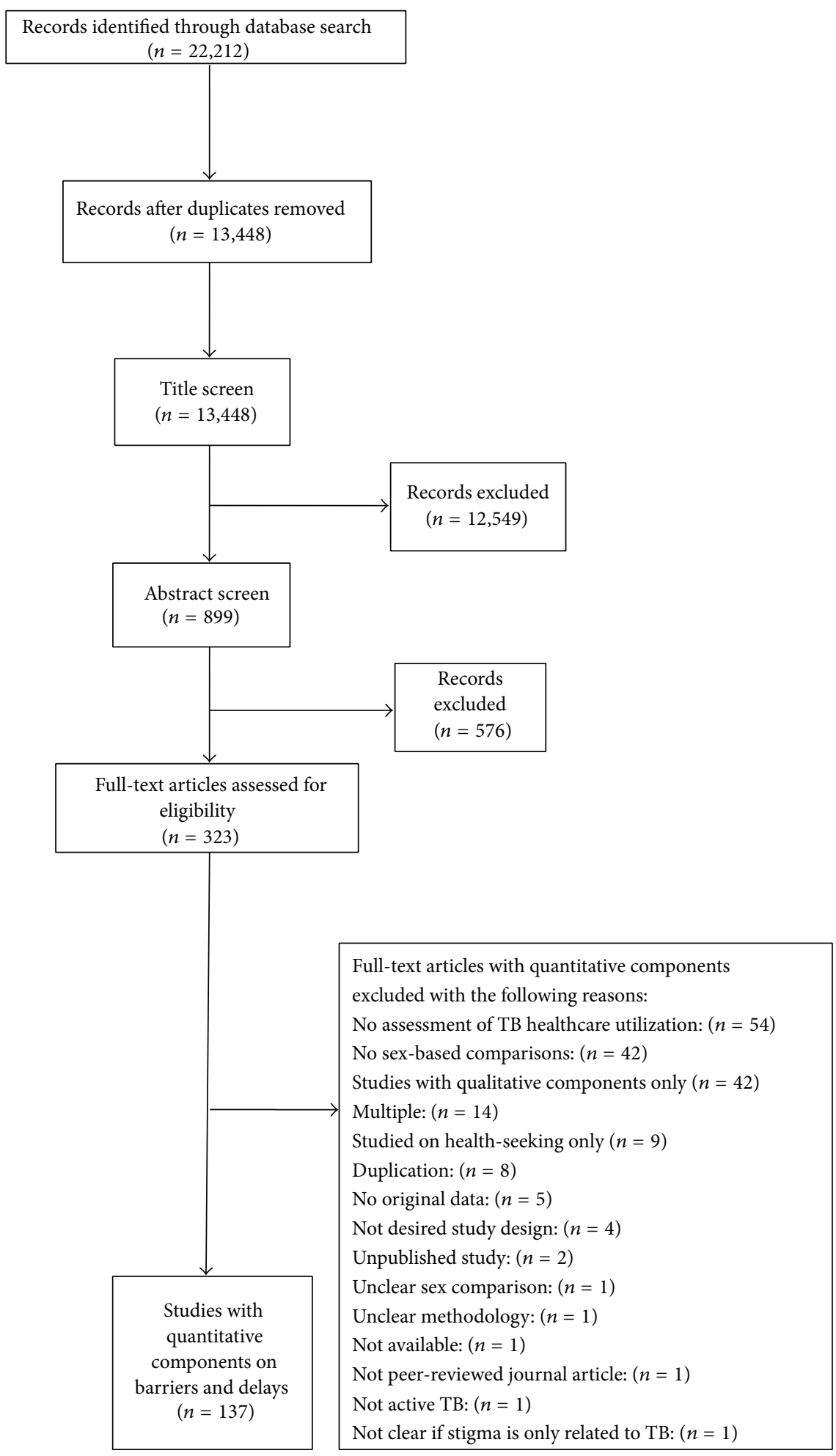

FIGURE 1: Study selection process.

household work); physical (distance, travel logistics, and/or access to TB care facilities); stigma (TB-specific sociocultural barriers arising from community or individual prejudice related to TB diagnosis or treatment, including social isolation, marriage prospects, fertility concerns, and association with HIV); health literacy (TB-related knowledge and education); and sociodemographic (age, race, rural versus urban residence, social caste, norms of practice, and social hierarchies). Provider-/system-level barriers were defined as any of the following: provider degree of suspicion for $\mathrm{TB}$, number 


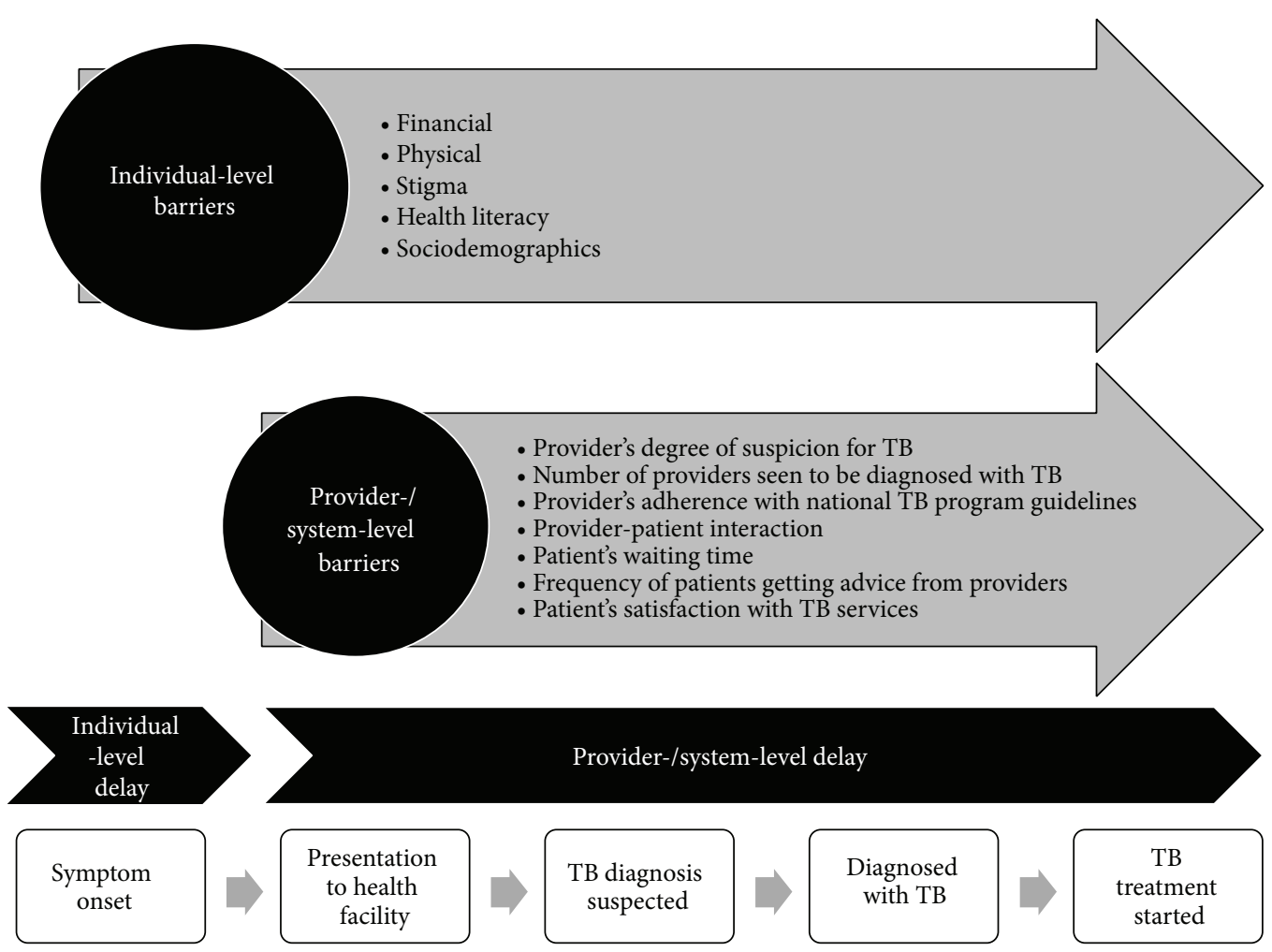

FIGURE 2: Conceptual framework illustrating barriers and delays that limit access to TB diagnostic and treatment services. The figure illustrates the conceptual framework of the tuberculosis (TB) care continuum from symptom onset to treatment initiation that we used to define barriers and delays that limit access to TB diagnostic and treatment services at the individual and provider/system levels. Individual-level barriers impact access to TB services along the full continuum of TB care, and provider-/system-level barriers impact access to TB services from patient presentation to any health care provider through TB treatment initiation. Barriers may contribute to delays between each step along the TB care continuum. Accordingly, we define individual-level delay as the delay between symptom onset and presentation to any health care provider; provider/system delay as the delay between presentation to any health care provider and diagnosis, the delay between presentation to any health care provider and treatment initiation or the delay between diagnosis and treatment initiation; and combined individual/provider/system delay as the delay between symptom onset and diagnosis or the delay between symptom onset and treatment initiation.

of providers seen before TB diagnosis, provider adherence to national TB program guidelines, provider-patient interaction, patient waiting time, frequency of getting advice, and patient satisfaction with TB services. Delay was defined as any time period between points along the TB care pathway under our conceptual framework from symptom onset to TB treatment initiation (Figure 2). Although barriers and delays are highly interrelated, few studies assess the contribution of barriers to delays quantitatively. Therefore, we present results for barriers and delays separately. We presented the impact of certain barriers on delays whenever possible.

\section{Results}

3.1. Study Characteristics. Our search strategy yielded 13,448 citations. Of these, 323 articles were reviewed in full-text form, and 137 studies met our selection criteria and were included in our review (Figure 1). Among the included studies, there was one $(<1 \%)$ cluster-randomized clinical trial [91], one $(<1 \%)$ pragmatic randomized controlled trial [55], eight (6\%) cohort studies [33,37, 67, 68, 87, 92, 136, 137], one
$(<1 \%)$ case-control study [69], and $126(92 \%)$ cross-sectional studies [12-32, 34-36, 38-54, 56-66, 70-86, 88-90, 93-135, $138-147,151]$. Most studies (76\%) assessed persons presenting for care with diagnosed or suspected TB, and the median sample size was 335 (IQR 190-1000) with women comprising less than half of the study population (median, interquartile range [IQR]: 42\%, 34-49\%). Most studies were published between 2000 and 2010, and two-thirds were conducted in Africa and Asia (Table 1).

3.2. Outcomes. Overall, the included studies reported on gender-related barriers and delays at the individual, provider/system, and combined individual/provider/system levels. Specifically, 71 (52\%) studies assessed individual-level barriers, 19 (14\%) studies assessed provider-/system-level barriers, and 7 (5\%) studies assessed combined individual/provider-/system-level barriers. Individual-level delays were assessed by $58(42 \%)$ studies, $37(27 \%)$ studies assessed provider/system-level delays, and 25 (18\%) studies assessed combined individual-/provider-/system-level delays. Key findings are summarized below by outcome type (barrier or 
TABLE 1: Characteristics of included studies.

\begin{tabular}{|c|c|}
\hline Study characteristic & Description \\
\hline Study design: $n(\%)$ & $\begin{array}{l}\text { Clustered randomized trial: } 1(<1 \%) \text {; } \\
\text { pragmatic randomized clinical trial: } 1 \\
(<1 \%) \text {; cohort study: } 8(6 \%) \text {; case-control } \\
\text { study: } 1(<1 \%) \text {; cross-sectional study: } 126 \\
(92 \%)\end{array}$ \\
\hline $\begin{array}{l}\text { Study population: } n \\
(\%)\end{array}$ & $\begin{array}{l}\text { Individuals with diagnosed/suspected TB } \\
\text { who presented to care: } 76 \% \text {; individuals } \\
\text { in the community or population: } 24 \%\end{array}$ \\
\hline $\begin{array}{l}\text { Year of publication: } \\
n(\%)\end{array}$ & $\begin{array}{l}2000-2010: 123(90 \%) ; 1990-1999: 11 \\
(8 \%) ; 1980-1989: 2(1 \%) ; 1970-1979: 1(1 \%)\end{array}$ \\
\hline $\begin{array}{l}\text { WHO regional } \\
\text { distribution: } n(\%)\end{array}$ & $\begin{array}{l}\text { AFRO: } 37 \text { (27\%); SEARO: } 31(23 \%) \text {; } \\
\text { WPRO: } 25 \text { (18\%); AMRO: } 17(13 \%) \text {; } \\
\text { EMRO: } 12(9 \%) \text {; EURO: } 11(8 \%) ; \text { multiple } \\
\text { regions: } 4 \text { (3\%) }\end{array}$ \\
\hline Sample size & $\begin{array}{l}\text { Range: } 39-209,560,379 ; \text { median (IQR): } \\
335(190-1,000)\end{array}$ \\
\hline $\begin{array}{l}\text { Proportion of } \\
\text { women }\end{array}$ & $\begin{array}{l}\text { Range: } 23-73 \% \text {; median (IQR): } 42 \% \\
(34-49 \%)\end{array}$ \\
\hline \multicolumn{2}{|c|}{$\begin{array}{l}\text { AFRO: African region; AMRO: region of the Americas; EMRO: Eastern } \\
\text { Mediterranean region; EURO: European region; IQR: interquartile range } \\
\text { SEARO: South East Asia region; TB: tuberculosis; WHO: World Health } \\
\text { Organization; WPRO: Western Pacific region. }\end{array}$} \\
\hline
\end{tabular}

delay) and level of impact (individual, provider/system, combined individual/provider/system) (Table 2 and Supplementary Table S1).

\subsection{Individual-Level Barriers}

3.3.1. Financial. Of 137 studies, 21 (15\%) examined genderrelated financial barriers to accessing TB services. Overall, a large number of studies found that women faced more financial barriers to seeking TB service than men. Fewer studies found either no difference in financial barriers between men and women or men faced greater financial barriers to accessing care (e.g., the opportunity cost of lost wages or income). While both men and women reported financial barriers to seeking TB services, the nature of these barriers differed. Women were more likely to be financially dependent on others $[19,26]$, unemployed, or without income $[16,17,20]$. Women also experienced greater healthcare seeking costs due to transport or the need for an escort [12, 17, 31], which may impact a woman's autonomy in seeking care. One study found that women may have also experienced greater financial barriers than men because they were more likely to see private providers than public providers [18]. The total direct costs of seeking TB diagnostic services as a proportion of income were higher for women than men in urban Zambia, largely because women had lower monthly incomes than men [13]. In Malawi, the indirect household costs of seeking care were higher for women [15].

3.3.2. Physical. Of 137 studies, only nine (7\%) explored gender-related physical barriers to accessing TB services. All nine studies found that distance and travel time to a health facility were similar for men and women. However, one study noted that distance to a clinic was more likely to result in delayed diagnosis among women than men [14].

3.3.3. Stigma. Of 137 studies, $18 \%$ investigated gender-related differences in TB-related stigma as a barrier to accessing TB diagnostic and treatment services. Of these, 12 found no gender-related differences in stigma, 11 found that women reported greater TB-related stigma than men, and two studies found that men experienced greater TB-related stigma than women. Only two studies specifically examined the impact of TB-related stigma on gender-based differences in individuallevel delays in seeking TB services; one study found that the impact of stigma on delay was greater among women than men [47], and the other study found no gender-based difference [48]. Four studies examined the impact of TBrelated stigma on marriage and marital prospects, and all reported that women were more likely than men to believe that TB would have an adverse impact on marriage prospects and marriage [35, 39, 43, 44].

3.3.4. Health Literacy. Of 137 studies, $36 \%$ described genderrelated differences in TB-related knowledge and education as barriers to accessing TB services, and the majority of these (80\%) examined differences in knowledge of the etiology, transmission, symptoms, diagnosis, and/or treatment of TB.

Of the 39 studies that assessed TB-related health literacy, 18 found that men and women had similar levels of TB-related knowledge, and, among those, six were conducted strictly in urban settings, and five were conducted in both urban and rural settings. Fourteen studies found that men had higher levels of TB-related knowledge than women; nine of these were conducted in strictly rural settings, and four were conducted in both rural and urban settings. Seven studies found that women had higher levels of TB-related knowledge than men; only one of these was conducted in a strictly rural setting. In addition, among ten studies that examined general educational attainment and literacy as barriers to accessing TB services, seven found that men were more educated and/or had higher literacy rates than women, and the remaining three studies found no gender-related differences.

Only two studies looked at the impact of TB-related knowledge and education on individual-level delays in presenting to TB services; one found that women suffered longer delays than men due to poor TB-related knowledge and education [14], and one found no gender-related differences [59]. One intervention trial found that, compared to women who did not receive brief instruction before submitting sputum samples, women who received instruction yielded significantly increased rates of both sputum positivity and return for submission of a second sputum sample. However, no significant changes were found among men who received such instruction [55]. This suggests that the intervention removed poor knowledge as a barrier for women to provide good sputum samples and to return for second sputum submission. Among two studies that examined the impact of TB-related knowledge on the likelihood of seeking tertiarylevel care, one found that TB-related knowledge was more predictive of seeking hospital care among men than among women [41], and one found no gender-related difference [61]. 
TABLE 2: Summary of quantitative gender-related findings by outcome type.

\begin{tabular}{|c|c|c|c|c|c|c|c|}
\hline \multirow{3}{*}{ Outcome type } & \multirow{3}{*}{$\begin{array}{l}\text { Number } \\
\text { of } \\
\text { studies }\end{array}$} & \multicolumn{4}{|c|}{ Gender difference } & \multicolumn{2}{|c|}{ No gender difference } \\
\hline & & \multicolumn{2}{|c|}{ Women $>$ Men } & \multicolumn{2}{|r|}{ Men $>$ Women } & \multirow[b]{2}{*}{$n(\%)$} & \multirow[b]{2}{*}{ List of studies } \\
\hline & & $n(\%)$ & List of studies & $n(\%)$ & List of studies & & \\
\hline \multicolumn{8}{|l|}{ Individual-level barriers } \\
\hline Financial & $21^{\mathrm{a}}$ & $11(52 \%)$ & $\begin{array}{c}{[12-14],[15]^{\mathrm{a}}} \\
\quad[16-22]\end{array}$ & $5(24 \%)$ & {$[23,24],[15]^{\mathrm{a}},[25,26]$} & $6(29 \%)$ & [27-32] \\
\hline Physical & 9 & $1(11 \%)$ & {$[14]$} & & & $8(89 \%)$ & {$[26,30-36]$} \\
\hline Stigma $^{\mathrm{b}}$ & 25 & $11(44 \%)$ & $\begin{array}{c}{[17,18,22,37-} \\
44]\end{array}$ & $2(8 \%)$ & {$[45,46]$} & $12(48 \%)$ & {$[24-26,35,47-54]$} \\
\hline Health literacy & 49 & $17(35 \%)$ & $\begin{array}{c}{[26,34-} \\
36,38,41,44 \\
50,55-63]\end{array}$ & $8(16 \%)$ & $\begin{array}{c}{[24,28,40,42,43,64-} \\
66]\end{array}$ & $24(50 \%)$ & $\begin{array}{l}{[14,20,22,25,30,37} \\
45-47,51-53,67-78]\end{array}$ \\
\hline Sociodemographic & 6 & $4(67 \%)$ & {$[17,79-81]$} & & & $2(33 \%)$ & {$[36,71]$} \\
\hline $\begin{array}{l}\text { Provider-/system- level } \\
\text { barriers }\end{array}$ & 19 & $8(42 \%)$ & $\begin{array}{c}{[17,29,37,} \\
82-86]\end{array}$ & & & $11(58 \%)$ & $\begin{array}{c}{[15,28,34,35,52,73,} \\
75,87-90]\end{array}$ \\
\hline $\begin{array}{l}\text { Combined individual-, } \\
\text { provider-, and } \\
\text { system-level barriers }\end{array}$ & 7 & $5(72 \%)$ & {$[29,91-94]$} & $1(14 \%)$ & [95] & $1(14 \%)$ & {$[18]$} \\
\hline Individual-level delay & 58 & $13(22 \%)$ & $\begin{array}{c}{[14,17,21,51} \\
73,79,96- \\
102]\end{array}$ & $7(12 \%)$ & {$[37,61,103-107]$} & $38(66 \%)$ & $\begin{array}{c}{[16,18-20,28,30-} \\
32,36,56,71,81,108- \\
133]\end{array}$ \\
\hline $\begin{array}{l}\text { Provider-/system-level } \\
\text { delay }\end{array}$ & 37 & $11(30 \%)$ & $\begin{array}{c}{[14,19,20,36} \\
81,85,120 \\
128,131,134 \\
135]\end{array}$ & $2(5 \%)$ & {$[35,101]$} & $24(65 \%)$ & $\begin{array}{c}{[16,18,32,33,79,96} \\
99,100,104,106,107 \\
113,115,117,118,121 \\
122,124,132,133,136- \\
139]\end{array}$ \\
\hline $\begin{array}{l}\text { Combined individual-, } \\
\text { provider-, and } \\
\text { system-level delay }\end{array}$ & $25^{\mathrm{c}}$ & $9(36 \%)$ & $\begin{array}{c}{[140],[141]^{c}} \\
{[27,32,36,79} \\
100,142,143]\end{array}$ & $1(4 \%)$ & {$[141]^{\mathrm{c}}$} & $17(68 \%)$ & $\begin{array}{c}{[33,69,110],[141]^{\mathrm{c}}} \\
{[35,86,114,117,124} \\
129,131-133,144-147]\end{array}$ \\
\hline
\end{tabular}

3.3.5. Sociodemographic. Only six (4\%) studies explored gender-related differences in sociodemographic barriers (factors of older age, family size, marital status, or caste) to accessing TB services. Older women were more likely than older men to either delay or not seek care [79-81]. Compared to men, lower caste was more likely to predict individuallevel delays among women [80], but family size had no gender-related differential impact on delays in seeking care [36]. Two studies explored the impact of being unmarried, separated, divorced, or widowed on seeking TB care $[17,71]$. Among TB patients in Kenya, there was no gender-related difference in the impact of marital status on seeking care for TB [71]. However, in Bangladesh, women were more likely to be adversely affected than men [17].

3.4. Provider-/System-Level Barriers. Of 137 studies, 19 (14\%) assessed gender-related barriers to accessing TB services at the provider and system levels. Overall, these studies were highly heterogeneous both in the barriers that were assessed and the findings.
Barriers to accessing diagnostic and/or treatment services at the provider and system levels were examined by nine (47\%) studies. Of these, eight studies examined genderrelated barriers to TB diagnosis and screening. In Thailand, it was found that providers were more likely to adhere to TB diagnostic guidelines among males with suspected TB compared to females with suspected TB [83]. In Malawi, males and females with suspected TB made a similar number of visits to a health facility before being diagnosed with TB $[15,90]$, and, in India, males and females with suspected TB were offered sputum smear microscopy with similar frequency [89]. In contrast, women in Gambia sought care from a larger number of healthcare providers to obtain a TB diagnosis than men [86], and, in Vietnam, women took more health-seeking actions for their symptoms than men but were offered sputum smear examinations significantly less often [21]. Among patients hospitalized and diagnosed with TB in the United States, women faced greater provider-/systemlevel delays in undergoing sputum smear microscopy than men [85]. However, among HIV-infected patients in the 
United States, men and women were screened for TB with similar frequency [87]. Only one study assessed genderrelated barriers to TB treatment following a diagnosis of TB and found no differences between male and female patients with respect to provider-related factors [28].

Gender-related differences in patient satisfaction with TB services were examined by seven (37\%) studies $[17,34,35,37$, 52, 73, 84]. In Nepal and Egypt, males and females with suspected TB had similar levels of satisfaction with TB services $[34,35]$. However, women in Egypt were less satisfied with drug availability than men, and women in Bangladesh and Syria were less satisfied with TB clinic hours, providers, and services than men, all of which were also predictors of healthseeking $[17,35,37]$. Compared to men, a greater proportion of women in Tanzania reported that a good provider-patient relationship was an important factor in their satisfaction with TB services [73]. Vietnamese TB patients reported no gender-related differences in the health education they received about their disease [52]. In another Tanzanian study where patients were randomized to community-based versus clinic-based TB treatment, male patients were more satisfied with community-based treatment than female patients [84]. Divided opinion regarding venue of treatment was noted in the study. Some patients preferred community-based treatment due to convenience, reduced transport costs, saved time, and reduced lost wages, whereas others preferred clinicbased treatment because it led to greater access to other clinical services and health education [84].

The remaining three studies reported on gender-related differences in health literacy among providers and TBrelated hospitalization. Two studies assessed gender-based differences in TB-related knowledge among health workers and found no gender-based differences among providers in Oman and Iraq where patients may be more likely to seek care from providers of the same sex $[75,88]$. One study in Tajikistan found that male TB patients were more likely to be hospitalized for treatment than female TB patients; other predictors of hospitalization in this study included positive sputum smear and availability of hospital beds [82].

3.5. Combined Individual-/Provider-/System-Level Barriers. Seven (5\%) studies assessed gender-related differences in TB case detection rates, which were impacted by combined individual-/provider-/system-level barriers. Communitybased active case finding was one strategy used to overcome combined level barriers to accessing $\mathrm{TB}$ diagnostic services $[152,153]$. Seven studies compared community-based active case finding versus passive case finding (i.e., self-referral). Of these, five found that community-based active case finding increased TB case detection rates more significantly among women than men [29, 91-94]; one found greater increases in case detection rates among men than women [95]; and one found no difference in the change of case detection rates between men and women [18].

3.6. Individual-Level Delays. Almost half of the included studies $(42 \%)$ appraised gender-related differences in individual-level delays. Of these, 38 found that symptomatic women were as likely as symptomatic men to delay or not seek TB services. However, among the 20 studies that found gender-related differences, 13 found that symptomatic women were more likely to delay or not seek TB services than symptomatic men, whereas seven studies found that symptomatic women were less likely to delay or not seek TB services than symptomatic men. The majority of studies were performed among study populations of persons who had already presented for care with diagnosed or suspected TB. Only five studies assessed persons with suspected TB in the general population. Of these, one study found that women were quicker to seek care for a prolonged cough [61], two studies found that women were slower to seek care [21,97], and two studies found no difference in delay by gender [56, $111]$.

3.7. Provider-/System-Level Delays. Of 137 studies, 37 (27\%) assessed gender-related differences in provider-/system-level delays in accessing TB services. The time between the presentation of a person with suspected $\mathrm{TB}$ to a health facility and TB diagnosis was most commonly assessed. Of 22 studies, 55\% found no gender-related difference in the delay from presentation to TB diagnosis. All of the remaining 10 studies found that women experienced longer delays than men. Among 13 studies that examined the delay from presentation to TB treatment initiation, nine found no gender-related difference, three found that women had longer delays than men $[14,81,135]$, and only one study found that men experienced longer delays than women [101]. Similarly, among seven studies that measured the delay between TB diagnosis and TB treatment initiation, four found no genderrelated difference $[33,79,104,137]$, two found that women had longer delays than men $[14,19]$, and only one found that men had longer delays than women [35].

3.8. Combined Individual-/Provider-/System-Level Delays. Of 137 studies, 25 (18\%) reported on gender-related differences in combined individual-/provider-/system-level delays. The delay between symptom onset and TB treatment initiation was most commonly assessed, and 13 out of these 18 (68\%) studies found no gender-related difference. When a genderrelated difference was observed, women faced longer delays than men $[27,79,100,140,143]$. One multicountry study found that, compared to men, women experienced longer delays in Yemen and shorter delays in Egypt but similar delays in other countries [141]. Among nine studies that assessed gender-related differences in the delay between symptom onset and TB diagnosis, 5 found no gender-related difference $[33,35,114,133,146]$, whereas four studies found that women experienced longer delays than men $[32,36,79,142]$.

3.9. Quality of Included Studies. We assessed 126 cross-sectional studies, one case-control study, and eight cohort studies using the STROBE criteria [148], and we assessed two randomized trials using the CONSORT criteria $[149,150]$. The majority of studies suffered from poor quality reporting of research design, methods, analyses, and results (see Supplementary Tables S2 and S3). Key weaknesses specific to and pervasive among the cross-sectional studies (92\% of included studies) were inadequate reporting regarding the 
numbers of males and females at each study stage from eligibility assessment through enrollment, participation, followup, and analysis; explanation of nonparticipation for males and females at each stage; information on prevalence of exposures and confounders among the male and female participants; presentation of unadjusted and confounderadjusted estimates for males and females; and explanation for selection of confounders for adjustment.

\section{Discussion}

Guided by a systematic review process, our review aimed to assess the quantitative evidence for gender-related differences in the barriers and delays that impact access to TB diagnostic and treatment services at the individual and provider/system levels. While, collectively, the included studies reported on barriers and delays at each level, more studies examined individual-level barriers and delays, and most studies surveyed persons presenting for care with diagnosed or suspected TB and were conducted in Africa and Asia. Overall, our review identified that many studies found no quantitative gender-related differences. However, when differences were reported, more studies found that women experienced greater barriers and longer delays at each level than men. In particular, many studies reported gender-related differences in financial, stigma, and health literacy barriers, which are interrelated and represent potential targets for genderspecific interventions that may be integrated into current and future TB service strategies.

While both genders experienced financial barriers to accessing TB services, the majority of studies that found gender-related differences reported that women experienced greater financial barriers than men, and the identified barriers were gender-specific. Specifically, the male role of primary income earner in many households prevented men from leaving work to access TB services, whereas, for women, their financial dependence on spouses and families limited access to TB services. Similar gender-related differences have been observed in financial barriers that limit access to diagnostic and treatment services for HIV and malaria [154-157]. Instituting more flexible hours and locations for TB services may help overcome the opportunity cost of lost wages and may improve case detection and treatment initiation among men. For women, barriers due to financial dependence may be compounded by the deprioritization of women's health care within the household below the needs of men and children. Because maternal health is prioritized by some households [158], efforts to integrate TB services with maternal healthcare may overcome some financial barriers and facilitate access to TB services among some women.

Regarding TB-related stigma, our review found that women were fearful of having a diagnosis of TB disclosed to their spouse, family, or community. Women experienced greater stigma than men, when gender-related differences were found. The impact of disease-related stigma has been well studied in the context of HIV, where anticipated or experienced stigma may lead patients to conceal symptoms, avoid or delay seeking care, hide their diagnoses, and be nonadherent with treatment [159-163]. Specifically, TB has been associated with dirtiness, immorality, substance abuse, and sexual promiscuity or deviancy [164-166], and, in communities with high rates of TB/HIV coinfection, TB may be further stigmatized by its association with HIV [167]. In addition to the psychosocial consequences of a TB diagnosis, our review also found that women were concerned about marital prospects and rejection by their spouse or families. Thus, TB-related stigma may also manifest as a financial barrier among those women who depend on spouses and family for financial support.

While stigma barriers may be addressed by interventions to improve TB-related health literacy, our review suggests that such programs may be particularly beneficial for women in rural areas. Among the included studies that reported gender difference in TB-related knowledge, men had greater TB-related knowledge and higher general literacy rates than women, and the majority of these (64\%) were conducted in rural settings. It may be important to examine the interaction between female literacy and the impact of poverty on care seeking as this interaction has impacted care seeking among women in the context of other health services [168, 169].

Although only a few studies assessed the impact of barriers on delays, individual-level barriers appear to impact individual-level delays in TB care seeking in gender-specific ways. Symptomatic women were more likely to delay or not seek care than symptomatic men when gender-related differences in individual-level delays were reported. Individuallevel TB-related stigma can represent both an obstacle and a motivation to seeking care [48], and marital status, which is intimately interlinked with issues of financial and social dependency as well as spousal and family support or rejection, also had a variable impact on gender-related differences in access to services [17, 71]. Regarding sociodemographic barriers, older age was a more significant barrier to accessing TB services among women than men [79, 81]. Given the complexity of these relationships, it is important to go beyond comparing the frequency and severity of individual-level barriers among women and men. Researchers and policymakers must also understand the impact of individual-level barriers on individual-level delays and how these barriers cause delays in accessing TB services among women and men. Qualitative studies may play an invaluable role here and inform researchers on the mechanisms of barriers and delays, which can be the points of intervention in the future.

Similarly, it is important to understand gender-related differences in provider-/system-level barriers and delays. In our review, fewer studies assessed barriers and delays at the provider/system level. However, when disparities were found, women were more likely to face barriers to accessing TB services than men. In addition, gender-specific individual barriers, such as financial and stigma barriers, may also impact the provider/system level but were not assessed by the studies included in our review. Surprisingly, in the context of other diseases, there are few reports on gender-related disparities in barriers and delays that limit access to care, particularly at the provider/system levels among patients in resource-limited settings. Provider-/system-level barriers and delays that lead to gender-related disparities in health 
often result from the lack of attention to the different needs of men and women while planning and providing health services, particularly with respect to service availability (e.g., geographical location, transportation available, service hours, and waiting time), affordability, acceptability (e.g., social and cultural competency, respect, privacy, confidentiality, and autonomy), and accountability [170,171]. Furthermore, health providers and health systems may compound individual-level and community-level disparities by failing to recognize that gender-based differences exist or by failing to acknowledge the need for corrective interventions [1].

In addition to the paucity of data on barriers and delays at the provider/system levels, our review revealed several other research gaps. To comprehensively identify genderrelated barriers and delays, study populations need to include persons with suspected TB who have not presented for care. There is also an urgent need for more granular analyses of gender disparities in accessing $\mathrm{TB}$ services for each step along the diagnostic and treatment continuum (i.e., symptom onset to symptom recognition; symptom recognition to seeking care; seeking care to TB diagnosis; TB diagnosis to notification; and notification to treatment initiation) at all levels. More generally, prospectively designed gender analyses are needed, and standardized ethnographic and cultural epidemiologic tools [5] also need to be used prospectively to systematically collect and compare gender-related sociocultural variables across studies, which may help to identify common as well as unique gender-related barriers.

The studies included in our review span different continents and differ among degree of urbanization and type of study population. Therefore, it is important to recognize heterogeneity while summarizing our findings. While most of the included studies were conducted in the Africa, South East Asia, and West Pacific regions, the frequency of some reported barriers by gender was not always proportional to numbers of studies from these regions. For example, financial barriers and delays at the individual and provider/system levels were reported proportionally by region, regardless of gender. However, women in South East Asia were noted to face more stigma, and women in West Pacific and both men and women in South East Asia had lower health literacy than persons from Africa (see Supplementary Table S4). These findings implicate region-specific priorities in interventions to improve access to TB care. Regarding study population type, included studies that assessed the general population (one quarter of the included studies) almost exclusively reported on stigma and health literacy barriers. Compared to studies among persons with diagnosed or suspected TB that found gender disparities, studies that assessed the general population were less likely to report that women face greater stigma and more likely to report that women have lower health literacy than men (see Supplementary Table S5). There is very little data to assess barriers and delays in different degrees of urbanization, as high percentage of studies were conducted in mixed urban and rural setting. However, studies from rural areas more frequently reported on worse health literacy among women (see Supplementary Table S6). The implication was already discussed above.
Many have called for more research on gender-related disparities in TB $[4,5,8,172,173]$. Accordingly, our systematic review aimed to assess the quantitative gender-related differences in barriers and delays that limit access to TB diagnostic and treatment services, which have been recognized as important for optimal TB control. However, a number of biases may have impacted our results and the individual studies that were included in our review. Although we strove to capture all high-quality studies addressing the topic of this review, some studies may have been missed, particularly those that were not published because they failed to document gender-related differences in accessing TB services, which may have resulted in an over representation of studies that demonstrated a difference (i.e., publication bias). In addition, our review was subject to biases introduced by the exclusion of non-English articles as studies from countries where English is not a primary language, particularly Latin American countries or East Asia, may be underrepresented. A noted limitation of the included studies was that the majority was cross-sectional studies and assessed patients with a confirmed TB diagnosis and/or those presenting for TB care. Those experiencing the greatest barriers to TB services are also least likely to be diagnosed with TB. Because persons presenting for care have already surmounted many individuallevel barriers, comparisons of gender-related differences in these study populations will suffer from selection bias. In addition, sample size among the included studies was highly variable, and the quality of study reporting was generally poor. Finally, the summary measures and definitions of barriers and delays were inconsistently used, making it difficult to weigh the relative importance of findings from the included studies or to conduct a meta-analysis or stratified analysis.

\section{Conclusions}

Overall, the scientific community is recognizing that genderrelated differences in health may be greater than is known and is increasingly prioritizing the need for routine genderrelated analyses [174-177]. Notably, the WHO has developed a strategy to mainstream the analysis of the role of gender in health and to monitor and address systemic genderrelated health inequities [178]. In the context of TB, gender analyses are critical to inform interventions to optimize the global impact of TB services. Our systematic review indicated that, when gender-related differences were found, women experienced greater barriers and longer delays than men and identified several gender-specific components within individual-level financial, stigma, and health literacy barriers that are amenable to intervention. However, our review also revealed research gaps and clearly highlighted that welldesigned gender analyses are critical. Finally, qualitative accounts of the gender differences presented here would inform mechanisms of barriers and provide insight for interventions.

\section{Conflict of Interests}

The authors declare that there is no conflict of interests regarding the publication of this paper. 


\section{Authors' Contribution}

Wei-Teng Yang, Celine R. Gounder, and Katherine N. McIntire wrote the manuscript and analyzed data. Wei-Teng Yang, Tokunbo Akande, and Jan-Walter De Neve abstracted data and made supplementary tables. Amita Gupta and Celine R. Gounder wrote the grant for funding from the World Health Organization. Aditya Chandrasekhar, Alan de Lima Pereira, Naveen Gummadi, and Santanu Samanta were involved in the title and abstract screening. All authors commented on and approved the paper.

\section{Acknowledgment}

This study was funded in part by a grant from the World Health Organization. The funders had no role in study design, data collection and analysis, preparation of the paper, or decision to publish. Wei-Teng Yang and Celine R. Gounder have joint first authorship.

\section{References}

[1] WHO, Global Tuberculosis Control 2012, WHO, 2012.

[2] P. Hudelson, "Gender differentials in tuberculosis: the role of socio-economic and cultural factors," Tubercle and Lung Disease, vol. 77, no. 5, pp. 391-400, 1996.

[3] A. Thorson and V. K. Diwan, "Gender inequalities in tuberculosis: aspects of infection, notification rates, and compliance," Current Opinion in Pulmonary Medicine, vol. 7, no. 3, pp. 165169, 2001.

[4] C. B. Holmes, H. Hausler, and P. Nunn, "A review of sex differences in the epidemiology of tuberculosis," International Journal of Tuberculosis and Lung Disease, vol. 2, no. 2, pp. 96-104, 1998.

[5] WHO, Gender and Tuberculosis, Gender and Health Research Series, WHO, 2004.

[6] M. Connolly and P. Nunn, "Women and tuberculosis," World Health Statistics Quarterly, vol. 49, no. 2, pp. 115-119, 1996.

[7] D. G. Storla, S. Yimer, and G. A. Bjune, "A systematic review of delay in the diagnosis and treatment of tuberculosis," BMC Public Health, vol. 8, article 15, 2008.

[8] M. W. Uplekar, S. Rangan, M. G. Weiss, J. Ogden, M. W. Borgdorff, and P. Hudelson, "Attention to gender issues in tuberculosis control," International Journal of Tuberculosis and Lung Disease, vol. 5, no. 3, pp. 220-224, 2001.

[9] J. Ogden, S. Rangan, M. Uplekar et al., "Shifting the paradigm in tuberculosis control: illustrations from India," International Journal of Tuberculosis and Lung Disease, vol. 3, no. 10, pp. 855861, 1999.

[10] I. Bates, C. Fenton, J. Gruber et al., "Vulnerability to malaria, tuberculosis, and HIV/AIDS infection and disease-part 1: determinants operating at individual and household level," The Lancet Infectious Diseases, vol. 4, no. 5, pp. 267-277, 2004.

[11] B. Vissandjee and M. Pai, "The socio-cultural challenge in public health interventions: the case of tuberculosis in India," International Journal of Public Health, vol. 52, no. 4, pp. 199-201, 2007.

[12] M. M. Mesfin, J. N. Newell, R. J. Madeley et al., "Cost implications of delays to tuberculosis diagnosis among pulmonary tuberculosis patients in Ethiopia," BMC Public Health, vol. 10, article 173, 2010.
[13] A. Aspler, D. Menzies, O. Oxlade et al., "Cost of tuberculosis diagnosis and treatment from the patient perspective in Lusaka, Zambia," International Journal of Tuberculosis and Lung Disease, vol. 12, no. 8, pp. 928-935, 2008.

[14] S. G. Mfinanga, B. K. Mutayoba, A. Kahwa et al., "The magnitude and factors associated with delays in management of smear positive tuberculosis in Dar es Salaam, Tanzania," BMC Health Services Research, vol. 8, article 158, 2008.

[15] J. R. Kemp, G. Mann, B. N. Simwaka, F. M. L. Salaniponi, and S. B. Squire, "Can Malawi's poor afford free tuberculosis services? Patient and household costs associated with a tuberculosis diagnosis in Lilongwe," Bulletin of the World Health Organization, vol. 85, no. 8, pp. 580-585, 2007.

[16] M. S. Kiwuwa, K. Charles, and M. K. Harriet, "Patient and health service delay in pulmonary tuberculosis patients attending a referral hospital: a cross-sectional study," BMC Public Health, vol. 5, article 122, 2005.

[17] G. Ahsan, J. Ahmed, P. Singhasivanon et al., "Gender difference in treatment seeking behaviors of tuberculosis cases in rural communities of Bangladesh," Southeast Asian Journal of Tropical Medicine and Public Health, vol. 35, no. 1, pp. 126-135, 2004.

[18] R. Balasubramanian, R. Garg, T. Santha et al., "Gender disparities in tuberculosis: report from a rural DOTS programme in south India," International Journal of Tuberculosis and Lung Disease, vol. 8, no. 3, pp. 323-332, 2004.

[19] M. R. Masjedi, A. Cheragvandi, M. Hadian, and A. A. Velayati, "Reasons for delay in the management of patients with pulmonary tuberculosis," Eastern Mediterranean Health Journal, vol. 8, no. 2-3, pp. 324-329, 2002.

[20] J. Ngamvithayapong, H. Yanai, A. Winkvist, and V. Diwan, "Health seeking behaviour and diagnosis for pulmonary tuberculosis in an HIV-epidemic mountainous area of Thailand," International Journal of Tuberculosis and Lung Disease, vol. 5, no. 11, pp. 1013-1020, 2001.

[21] A. Thorson, N. P. Hoa, and N. H. Long, "Health-seeking behaviour of individuals with a cough of more than 3 weeks," The Lancet, vol. 356, no. 9244, pp. 1823-1824, 2000.

[22] R. Rajeswari, R. Balasubramanian, M. Muniyandi, S. Geetharamani, X. Thresa, and P. Venkatesan, "Socio-economic impact of tuberculosis on patients and family in India," International Journal of Tuberculosis and Lung Disease, vol. 3, no. 10, pp. 869877, 1999.

[23] A. Vassall, A. Seme, P. Compernolle, and F. Meheus, "Patient costs of accessing collaborative tuberculosis and human immunodefi ciency virus interventions in Ethiopia," International Journal of Tuberculosis and Lung Disease, vol. 14, no. 5, pp. 604610, 2010.

[24] M. G. Weiss, D. Somma, F. Karim et al., "Cultural epidemiology of $\mathrm{TB}$ with reference to gender in Bangladesh, India and Malawi," International Journal of Tuberculosis and Lung Disease, vol. 12, no. 7, pp. 837-847, 2008.

[25] S. R. Atre, A. M. Kudale, S. N. Morankar, S. G. Rangan, and M. G. Weiss, "Cultural concepts of tuberculosis and gender among the general population without tuberculosis in rural Maharashtra, India," Tropical Medicine and International Health, vol. 9, no. 11, pp. 1228-1238, 2004.

[26] M. A. H. Salim, E. Declercq, A. van Deun, and K. A. R. Saki, "Gender differences in tuberculosis: a prevalence survey done in Bangladesh," International Journal of Tuberculosis and Lung Disease, vol. 8, no. 8, pp. 952-957, 2004.

[27] M. Lambert, R. Delgado, G. Michaux, A. Volz, N. Speybroeck, and P. van der Stuyft, "Delays to treatment and out-of-pocket 
medical expenditure for tuberculosis patients, in an urban area of South America," Annals of Tropical Medicine and Parasitology, vol. 99, no. 8, pp. 781-787, 2005.

[28] R. Dandona, L. Dandona, A. Mishra, S. Dhingra, K. Venkatagopalakrishna, and L. S. Chauhan, "Utilization of and barriers to public sector tuberculosis services in India," National Medical Journal of India, vol. 17, no. 6, pp. 292-299, 2004.

[29] A. Thorson, N. P. Hoa, N. H. Long, P. Allebeck, and V. K. Diwan, "Do women with tuberculosis have a lower likelihood of getting diagnosed? Prevalence and case detection of sputum smear positive pulmonary TB, a population-based study from Vietnam," Journal of Clinical Epidemiology, vol. 57, no. 4, pp. 398-402, 2004.

[30] P. Godfrey-Faussett, H. Kaunda, J. Kamanga et al., "Why do patients with a cough delay seeking care at Lusaka urban health centres? A health systems research approach," International Journal of Tuberculosis and Lung Disease, vol. 6, no. 9, pp. 796805, 2002.

[31] H. Sadiq and A. D. Muynck, "Health care seeking behavior of pulmonary tuberculosis patients visiting TB Center Rawalpindi," Journal of the Pakistan Medical Association, vol. 51, no. 1, pp. 10-16, 2001.

[32] M. Yamasaki-Nakagawa, K. Ozasa, N. Yamada et al., "Gender difference in delays to diagnosis and health care seeking behavior in a rural area of Nepal," International Journal of Tuberculosis and Lung Disease, vol. 5, no. 1, pp. 24-31, 2001.

[33] M. Jiménez-Corona, L. García-García, K. DeRiemer et al., "Gender differentials of pulmonary tuberculosis transmission and reactivation in an endemic area," Thorax, vol. 61, no. 4, pp. 348-353, 2006.

[34] S. K. Tiwari and E. J. Love, "Gender and tuberculosis control in armed conflict areas in Nepal," International Medical Journal, vol. 14, no. 4, pp. 265-271, 2007.

[35] M. I. Kamel, S. Rashed, N. Foda, A. Mohie, and M. Loutfy, "Gender differences in health care utilization and outcome of respiratory tuberculosis in Alexandria," Eastern Mediterranean Health Journal, vol. 9, no. 4, pp. 741-756, 2003.

[36] N. H. Long, E. Johansson, K. Lönnroth, B. Eriksson, A. Winkvist, and V. K. Diwan, "Longer delays in tuberculosis diagnosis among women in Vietnam," International Journal of Tuberculosis and Lung Disease, vol. 3, no. 5, pp. 388-393, 1999.

[37] H. Bashour and F. Mamaree, "Gender differences and tuberculosis in the Syrian Arab Republic: patients' attitudes, compliance and outcomes," Eastern Mediterranean Health Journal, vol. 9, no. 4, pp. 757-768, 2003.

[38] A. Deribew, G. Abebe, L. Apers et al., "Prejudice and misconceptions about tuberculosis and HIV in rural and urban communities in Ethiopia: a challenge for the TB/HIV control program," BMC Public Health, vol. 10, article 400, 2010.

[39] V. K. Dhingra and S. Khan, "A sociological study on stigma among TB patients in Delhi," Indian Journal of Tuberculosis, vol. 57, no. 1, pp. 12-18, 2010.

[40] M. Berisha, V. Zheki, D. Zadzhmi, S. Gashi, R. Hokha, and I. Begoli, "Level of knowledge regarding tuberculosis and stigma among patients suffering from tuberculosis," Georgian Medical News, no. 166, pp. 89-93, 2009.

[41] N. P. Hoa, N. T. K. Chuc, and A. Thorson, "Knowledge, attitudes, and practices about tuberculosis and choice of communication channels in a rural community in Vietnam," Health Policy, vol. 90, no. 1, pp. 8-12, 2009.

[42] S. M. Marks, N. Deluca, and W. Walton, "Knowledge, attitudes and risk perceptions about tuberculosis: US national health interview survey," International Journal of Tuberculosis and Lung Disease, vol. 12, no. 11, pp. 1261-1267, 2008.

[43] F. Karim, A. M. R. Chowdhury, A. Islam, and M. G. Weiss, "Stigma, gender, and their impact on patients with tuberculosis in rural Bangladesh," Anthropology and Medicine, vol. 14, no. 2, pp. 139-151, 2007.

[44] H. Getahun and D. Aragaw, "Tuberculosis in rural northwest Ethiopia: community perspective," Ethiopian Medical Journal, vol. 39, no. 4, pp. 283-291, 2001.

[45] R. X. Armijos, M. M. Weigel, M. Qincha, and B. Ulloa, “The meaning and consequences of tuberculosis for an at-risk urban group in Ecuador," Pan American Journal of Public Health, vol. 23, no. 3, pp. 188-197, 2008.

[46] M. S. Westaway, "Knowledge, beliefs and feelings about tuberculosis," Health Education Research, vol. 4, no. 2, pp. 205-211, 1989.

[47] J. M. Cramm, H. J. Finkenflügel, V. Møller, and A. P. Nieboer, "TB treatment initiation and adherence in a South African community influenced more by perceptions than by knowledge of tuberculosis," BMC Public Health, vol. 10, article 72, 2010.

[48] P. Pungrassami, A. M. Kipp, P. W. Stewart, V. Chongsuvivatwong, R. P. Strauss, and A. van Rie, "Tuberculosis and AIDS stigma among patients who delay seeking care for tuberculosis symptoms," International Journal of Tuberculosis and Lung Disease, vol. 14, no. 2, pp. 181-187, 2010.

[49] S. Atre, A. Kudale, S. Morankar, D. Gosoniu, and M. G. Weiss, "Gender and community views of stigma and tuberculosis in rural Maharashtra, India," Global Public Health, vol. 6, no. 1, pp. 56-71, 2011.

[50] S. H. Lu, B. C. Tian, X. P. Kang et al., "Public awareness of tuberculosis in China: a national survey of 69253 subjects," International Journal of Tuberculosis and Lung Disease, vol. 13, no. 12, pp. 1493-1499, 2009.

[51] S. A. Qureshi, O. Morkve, and T. Mustafa, "Patient and health system delays: health-care seeking behaviour among pulmonary tuberculosis patients in Pakistan," Journal of the Pakistan Medical Association, vol. 58, no. 6, pp. 318-321, 2008.

[52] N. P. Hoa, V. K. Diwan, N. V. Co, and A. E. K. Thorson, "Knowledge about tuberculosis and its treatment among new pulmonary TB patients in the north and central regions of Vietnam," International Journal of Tuberculosis and Lung Disease, vol. 8, no. 5, pp. 603-608, 2004.

[53] T. K. Koay, "Knowledge and attitudes towards tuberculosis among the people living in Kudat district, Sabah," Medical Journal of Malaysia, vol. 59, no. 4, pp. 502-511, 2004.

[54] N. Shetty, M. Shemko, and A. Abbas, "Knowledge, attitudes and practices regarding tuberculosis among immigrants of Somalian ethnic origin in London: a cross-sectional study," Communicable Disease and Public Health, vol. 7, no. 1, pp. 77-82, 2004.

[55] M. S. Khan, O. Dar, C. Sismanidis, K. Shah, and P. GodfreyFaussett, "Improvement of tuberculosis case detection and reduction of discrepancies between men and women by simple sputum-submission instructions: a pragmatic randomised controlled trial," The Lancet, vol. 369, no. 9577, pp. 1955-1960, 2007.

[56] J. M. Wang, Y. Fei, H. B. Shen, and B. Xu, "Gender difference in knowledge of tuberculosis and associated health-care seeking behaviors: a cross-sectional study in a rural area of China," $B M C$ Public Health, vol. 8, article 354, 2008.

[57] N. Sharma, R. Malhotra, D. K. Taneja, R. Saha, and G. K. Ingle, "Awareness and perception about tuberculosis in the general 
population of Delhi," Asia-Pacific Journal of Public Health, vol. 19, no. 2, pp. 10-15, 2007.

[58] T. H. Zhang, X. Y. Liu, H. Bromley, and S. L. Tang, "Perceptions of tuberculosis and health seeking behaviour in rural Inner Mongolia, China," Health Policy, vol. 81, no. 2-3, pp. 155-165, 2007.

[59] J. Date and K. Okita, "Gender and literacy: factors related to diagnostic delay and unsuccessful treatment of tuberculosis in the mountainous area of Yemen," International Journal of Tuberculosis and Lung Disease, vol. 9, no. 6, pp. 680-685, 2005.

[60] M. Agboatwalla, G. N. Kazi, S. K. Shah, and M. Tariq, "Gender perspectives on knowledge and practices regarding tuberculosis in urban and rural areas in Pakistan," Eastern Mediterranean Health Journal, vol. 9, no. 4, pp. 732-740, 2003.

[61] N. P. Hoa, A. E. K. Thorson, N. H. Long, and V. K. Diwan, "Knowledge of tuberculosis and associated health-seeking behaviour among rural Vietnamese adults with a cough for at least three weeks," Scandinavian Journal of Public Health, vol. 62, pp. 59-65, 2003.

[62] R. Malhotra, D. K. Taneja, V. K. Dhingra, S. Rajpal, and M. Mehra, "Awareness regarding tuberculosis in a rural population of Delhi," Indian Journal of Community Medicine, vol. 27, no. 2, pp. 62-68, 2002.

[63] J. S. Marinac, S. K. Willsie, D. McBride, and S. C. Hamburger, "Knowledge of tuberculosis in high-risk populations: survey of inner city minorities," International Journal of Tuberculosis and Lung Disease, vol. 2, no. 10, pp. 804-810, 1998.

[64] B. Chimbanrai, W. Fungladda, J. Kaewkungwal, and U. Silachamroon, "Treatment-seeking behaviors and improvement in adherence to treatment regimen of tuberculosis patients using intensive triad-model program, Thailand," Southeast Asian Journal of Tropical Medicine and Public Health, vol. 39, no. 3, pp. 526-541, 2008.

[65] S. Promtussananon and K. Peltzer, "Perceptions of tuberculosis: attributions of cause, suggested means of risk reduction, and preferred treatment in the Limpopo province, South Africa," Journal of Health, Population and Nutrition, vol. 23, no. 1, pp. 74-81, 2005.

[66] R. L. Ailinger, H. Lasus, and M. Dear, "Americans' knowledge and perceived risk of tuberculosis," Public Health Nursing, vol. 20, no. 3, pp. 211-215, 2003.

[67] C. K. Liam, K. H. Lim, C. M. M. Wong, and B. G. Tang, "Attitudes and knowledge of newly diagnosed tuberculosis patients regarding the disease, and factors affecting treatment compliance," International Journal of Tuberculosis and Lung Disease, vol. 3, no. 4, pp. 300-309, 1999.

[68] R. Rajeswari, M. Muniyandi, R. Balasubramanian, and P. R. Narayanan, "Perceptions of tuberculosis patients about their physical, mental and social well-being: a field report from south India," Social Science and Medicine, vol. 60, no. 8, pp. 1845-1853, 2005.

[69] A. C. Crampin, J. R. Glynn, S. Floyd et al., "Tuberculosis and gender: exploring the patterns in a case control study in Malawi," International Journal of Tuberculosis and Lung Disease, vol. 8, no. 2, pp. 194-203, 2004.

[70] M. U. Mushtaq, M. A. Majrooh, W. Ahmad et al., "Knowledge, attitudes and practices regarding tuberculosis in two districts of Punjab, Pakistan," International Journal of Tuberculosis and Lung Disease, vol. 14, no. 3, pp. 303-310, 2010.

[71] P. O. Ayuo, L. O. Diero, W. D. Owino-Ongor, and A. W. Mwangi, "Causes of delay in diagnosis of pulmonary tuberculosis in patients attending a referral hospital in Western Kenya,' East African Medical Journal, vol. 85, no. 6, pp. 263-268, 2008.

[72] P. Brassard, K. K. Anderson, D. Menzies, K. Schwartzman, and M. E. Macdonald, "Knowledge and perceptions of tuberculosis among a sample of urban aboriginal people," Journal of Community Health, vol. 33, no. 4, pp. 192-198, 2008.

[73] A. M. Kilale, A. K. Mushi, L. A. Lema et al., "Perceptions of tuberculosis and treatment seeking behaviour in Ilala and Kinondoni Municipalities in Tanzania," Tanzania Journal of Health Research, vol. 10, no. 2, pp. 89-94, 2008.

[74] A. Katamba, D. B. Neuhauser, K. A. Smyth, F. Adatu, E. Katabira, and C. C. Whalen, "Patients perceived stigma associated with community-based directly observed therapy of tuberculosis in Uganda," East African Medical Journal, vol. 82, no. 7, pp. 337342, 2005.

[75] D. S. Hashim, W. Al Kubaisy, and A. Al Dulayme, "Knowledge, attitudes and practices survey among health care workers and tuberculosis patients in Iraq," Eastern Mediterranean Health Journal, vol. 9, no. 4, pp. 718-731, 2003.

[76] E. R. Wandwalo and O. Morkve, "Knowledge of disease and treatment among tuberculosis patients in Mwanza, Tanzania," International Journal of Tuberculosis and Lung Disease, vol. 4, no. 11, pp. 1041-1046, 2000.

[77] J. P. Tulsky, M. C. White, J. A. Young, R. Meakin, and A. R. Moss, "Street talk: knowledge and attitudes about tuberculosis and tuberculosis control among homeless adults," International Journal of Tuberculosis and Lung Disease, vol. 3, no. 6, pp. 528$533,1999$.

[78] D. Jenkins, "Tuberculosis: the Native Indian viewpoint on its prevention, diagnosis, and treatment," Preventive Medicine, vol. 6, no. 4, pp. 545-555, 1977.

[79] F. Karim, M. A. Islam, A. M. R. Chowdhury, E. Johansson, and V. K. Diwan, "Gender differences in delays in diagnosis and treatment of tuberculosis," Health Policy and Planning, vol. 22, no. 5, pp. 329-334, 2007.

[80] A. Kaulagekar and A. Radkar, "Social status makes a difference: tuberculosis scenario during national family health survey-2," The Indian Journal of Tuberculosis, vol. 54, no. 1, pp. 17-23, 2007.

[81] J. Ward, V. Siskind, and A. Konstantinos, "Patient and health care system delays in Queensland tuberculosis patients, 19851998," International Journal of Tuberculosis and Lung Disease, vol. 5, no. 11, pp. 1021-1027, 2001.

[82] C. Thierfelder, K. Makowiecka, T. Vinichenko, R. Ayé, P. Edwards, and K. Wyss, "Management of pulmonary tuberculosis in Tajikistan: which factors determine hospitalization?" Tropical Medicine and International Health, vol. 13, no. 11, pp. 13641371, 2008.

[83] W. Thongraung, V. Chongsuvivatwong, and P. Pungrassamee, "Multilevel factors affecting tuberculosis diagnosis and initial treatment," Journal of Evaluation in Clinical Practice, vol. 14, no. 3, pp. 378-384, 2008.

[84] E. Wandwalo, E. Makundi, T. Hasler, and O. Morkve, "Acceptability of community and health facility-based directly observed treatment of tuberculosis in Tanzanian urban setting," Health Policy, vol. 78, no. 2-3, pp. 284-294, 2006.

[85] J. Rozovsky-Weinberger, J. P. Parada, L. Phan et al., "Delays in suspicion and isolation among hospitalized persons with pulmonary tuberculosis at public and private US hospitals during 1996 to 1999," Chest, vol. 127, no. 1, pp. 205-212, 2005.

[86] C. Lienhardt, J. Rowley, K. Manneh et al., "Factors affecting time delay to treatment in a tuberculosis control programme in a 
sub-Saharan African country: the experience of the Gambia," International Journal of Tuberculosis and Lung Disease, vol. 5, no. 3, pp. 233-239, 2001.

[87] T. L. Box, M. Olsen, E. Z. Oddone, and S. A. Keitz, "Healthcare access and utilization by patients infected with human immunodeficiency virus: does gender matter?" Journal of Women's Health, vol. 12, no. 4, pp. 391-397, 2003.

[88] A. A. Al-Maniri, O. A. Al-Rawas, F. Al-Ajmi, A. de Costa, B. Eriksson, and V. K. Diwan, "Tuberculosis suspicion and knowledge among private and public general practitioners: questionnaire Based Study in Oman," BMC Public Health, vol. 8, article $177,2008$.

[89] G. Fochsen, K. Deshpande, V. Diwan, A. Mishra, V. K. Diwan, and A. Thorson, "Health care seeking among individuals with cough and tuberculosis: a population-based study from rural India," International Journal of Tuberculosis and Lung Disease, vol. 10, no. 9, pp. 995-1000, 2006.

[90] A. D. Harries, T. E. Nyirenda, P. Godfrey-Faussett, and F. M. Salaniponi, "Defining and assessing the maximum number of visits patients should make to a health facility to obtain a diagnosis of pulmonary tuberculosis," International Journal of Tuberculosis and Lung Disease, vol. 7, no. 10, pp. 953-958, 2003.

[91] D. G. Datiko and B. Lindtjørn, "Health extension workers improve tuberculosis case detection and treatment success in southern Ethiopia: a community randomized trial," PLoS ONE, vol. 4, no. 5, Article ID e5443, 2009.

[92] A. Cassels, E. Heineman, S. LeClerq, P. K. Gurung, and C. B. Rahut, "Tuberculosis case-finding in Eastern Nepal," Tubercle, vol. 63, no. 3, pp. 175-185, 1982.

[93] S. Yimer, C. Holm-Hansen, T. Yimaldu, and G. Bjune, "Evaluating an active case-fi nding strategy to identify smear-positive tuberculosis in rural Ethiopia," International Journal of Tuberculosis and Lung Disease, vol. 13, no. 11, pp. 1399-1404, 2009.

[94] M. C. Becerra, I. F. Pachao-Torreblanca, J. Bayona et al., "Expanding tuberculosis case detection by screening household contacts," Public Health Reports, vol. 120, no. 3, pp. 271-277, 2005.

[95] T. Santha, G. Renu, T. R. Frieden et al., "Are community surveys to detect tuberculosis in high prevalence areas useful? Results of a comparative study from Tiruvallur District, South India," International Journal of Tuberculosis and Lung Disease, vol. 7, no. 3, pp. 258-265, 2003.

[96] R. Basnet, S. G. Hinderaker, D. Enarson, P. Malla, and O. Mørkve, "Delay in the diagnosis of tuberculosis in Nepal," BMC Public Health, vol. 9, article 236, 2009.

[97] K. A. Rumman, N. A. Sabra, F. Bakri, A. Seita, and A. Bassili, "Prevalence of tuberculosis suspects and their healthcareseeking behavior in urban and rural Jordan," The American Journal of Tropical Medicine and Hygiene, vol. 79, no. 4, pp. 545551, 2008.

[98] Y. Wang, Q. Long, Q. Liu, R. Tolhurst, and S. L. Tang, “Treatment seeking for symptoms suggestive of TB: comparison between migrants and permanent urban residents in Chongqing, China," Tropical Medicine and International Health, vol. 13, no. 7, pp. 927-933, 2008.

[99] C. T. Chang and A. Esterman, "Diagnostic delay among pulmonary tuberculosis patients in Sarawak, Malaysia: a crosssectional study," Rural and Remote Health, vol. 7, no. 2, p. 667, 2007.

[100] N. T. Huong, M. Vree, B. D. Duong et al., "Delays in the diagnosis and treatment of tuberculosis patients in Vietnam: a crosssectional study," BMC Public Health, vol. 7, article 110, 2007.
[101] T. Wondimu, K. W. Michael, K. Wondwossen, and G. Sofonias, "Delay in initiating tuberculosis treatment and factors associated among pulmonary tuberculosis patients in East Wollega, Western Ethiopia," Ethiopian Journal of Health Development, vol. 21, no. 2, pp. 148-156, 2007.

[102] M. Díez, M. J. Bleda, J. Alcaide et al., "Determinants of patient delay among tuberculosis cases in Spain," European Journal of Public Health, vol. 14, no. 2, pp. 151-155, 2004.

[103] C. M. Ford, A. M. Bayer, R. H. Gilman et al., "Factors associated with delayed tuberculosis test-seeking behavior in the Peruvian Amazon," The American Journal of Tropical Medicine and Hygiene, vol. 81, no. 6, pp. 1097-1102, 2009.

[104] G. Meintjes, H. Schoeman, C. Morroni, D. Wilson, and G. Maartens, "Patient and provider delay in tuberculosis suspects from communities with a high HIV prevalence in South Africa: a cross-sectional study," BMC Infectious Diseases, vol. 8, article 72, 2008.

[105] L. Pehme, K. Rahu, M. Rahu, and A. Altraja, "Factors related to patient delay in pulmonary tuberculosis in Estonia," Scandinavian Journal of Infectious Diseases, vol. 38, no. 11-12, pp. 10171022, 2006.

[106] R. Rajeswari, V. Chandrasekaran, M. Suhadev, S. Sivasubramaniam, G. Sudha, and G. Renu, "Factors associated with patient and health system delays in the diagnosis of tuberculosis in South India," International Journal of Tuberculosis and Lung Disease, vol. 6, no. 9, pp. 789-795, 2002.

[107] L. N. Hooi, "Case-finding for pulmonary tuberculosis in Penang," Medical Journal of Malaysia, vol. 49, no. 3, pp. 223-230, 1994.

[108] A. A. Gele, G. Bjune, and F. Abebe, "Pastoralism and delay in diagnosis of TB in Ethiopia," BMC Public Health, vol. 9, article 5, 2009.

[109] M. M. Mesfin, J. N. Newell, J. D. Walley, A. Gessessew, and R. J. Madeley, "Delayed consultation among pulmonary tuberculosis patients: a cross sectional study of 10 DOTS districts of Ethiopia," BMC Public Health, vol. 9, article 53, 2009.

[110] E. S. Ngadaya, G. S. Mfinanga, E. R. Wandwalo, and O. Morkve, "Delay in Tuberculosis case detection in Pwani region, Tanzania. A cross sectional study," BMC Health Services Research, vol. 9, article 196, 2009.

[111] S. Yimer, C. Holm-Hansen, T. Yimaldu, and G. Bjune, "Health care seeking among pulmonary tuberculosis suspects and patients in rural Ethiopia: a community-based study," $B M C$ Public Health, vol. 9, article 454, 2009.

[112] X. Lin, V. Chongsuvivatwong, A. Geater, and R. Lijuan, “The effect of geographical distance on TB patient delays in a mountainous province of China," International Journal of Tuberculosis and Lung Disease, vol. 12, no. 3, pp. 288-293, 2008.

[113] N. Lorent, P. Mugwaneza, J. Mugabekazi et al., "Risk factors for delay in the diagnosis and treatment of tuberculosis at a referral hospital in Rwanda," International Journal of Tuberculosis and Lung Disease, vol. 12, no. 4, pp. 392-396, 2008.

[114] F. Maamari, "Case-finding tuberculosis patients: diagnostic and treatment delays and their determinants," Eastern Mediterranean Health Journal, vol. 14, no. 3, pp. 531-545, 2008.

[115] J. M. Selvam, F. Wares, M. Perumal et al., "Health-seeking behaviour of new smear-positive TB patients under a DOTS programme in Tamil Nadu, India, 2003," International Journal of Tuberculosis and Lung Disease, vol. 11, no. 2, pp. 161-167, 2007.

[116] B. Xu, V. K. Diwan, and L. Bogg, "Access to tuberculosis care: what did chronic cough patients experience in the way of 
healthcare-seeking?" Scandinavian Journal of Public Health, vol. 35, no. 4, pp. 396-402, 2007.

[117] M. G. Farah, J. H. Rygh, T. W. Steen, R. Selmer, E. Heldal, and G. Bjune, "Patient and health care system delays in the start of tuberculosis treatment in Norway," BMC Infectious Diseases, vol. 6, article 33, 2006.

[118] M. Rojpibulstit, J. Kanjanakiritamrong, and V. Chongsuvivatwong, "Patient and health system delays in the diagnosis of tuberculosis in Southern Thailand after health care reform," International Journal of Tuberculosis and Lung Disease, vol. 10, no. 4, pp. 422-428, 2006.

[119] M. J. van der Werf, Y. Chechulin, O. B. Yegorova et al., "Health care seeking behaviour for tuberculosis symptoms in Kiev City, Ukraine," International Journal of Tuberculosis and Lung Disease, vol. 10, no. 4, pp. 390-395, 2006.

[120] G. Cheng, R. Tolhurst, R. Z. Li, Q. Y. Meng, and S. Tang, "Factors affecting delays in tuberculosis diagnosis in rural China: a case study in four counties in Shandong Province," Transactions of the Royal Society of Tropical Medicine and Hygiene, vol. 99, no. 5, pp. 355-362, 2005.

[121] B. Xu, Q. W. Jiang, Y. Xiu, and V. K. Diwan, "Diagnostic delays in access to tuberculosis care in counties with or without the national tuberculosis control programme in rural China," International Journal of Tuberculosis and Lung Disease, vol. 9, no. 7, pp. 784-790, 2005.

[122] S. Yimer, G. Bjune, and G. Alene, "Diagnostic and treatment delay among pulmonary tuberculosis patients in Ethiopia: a cross sectional study," BMC Infectious Diseases, vol. 5, article 112, 2005.

[123] O. O. Odusanya and J. O. Babafemi, "Patterns of delays amongst pulmonary tuberculosis patients in Lagos, Nigeria," BMC Public Health, vol. 4, article 18, 2004.

[124] S. Paynter, A. Hayward, P. Wilkinson, S. Lozewicz, and R. Coker, "Patient and health service delays in initiating treatment for patients with pulmonary tuberculosis: retrospective cohort study," International Journal of Tuberculosis and Lung Disease, vol. 8, no. 2, pp. 180-185, 2004.

[125] G. Sudha, C. Nirupa, M. Rajasakthivel et al., "Factors influencing the care-seeking behaviour of chest symptomatics: a community-based study involving rural and urban population in Tamil Nadu, South India," Tropical Medicine and International Health, vol. 8, no. 4, pp. 336-341, 2003.

[126] M. Demissie, B. Lindtjorn, and Y. Berhane, "Patient and health service delay in the diagnosis of pulmonary tuberculosis in Ethiopia," BMC Public Health, vol. 2, no. 1, p. 23, 2002.

[127] V. K. Dhingra, S. Rajpal, D. K. Taneja, D. Kalra, and R. Malhotra, "Health care seeking pattern of tuberculosis patients attending an urban TB clinic in Delhi," Journal of Communicable Diseases, vol. 34, no. 3, pp. 185-192, 2002.

[128] P. M. Pronyk, M. B. Makhubele, J. R. Hargreaves, S. M. Tollman, and H. P. Hausler, "Assessing health seeking behaviour among tuberculosis patients in rural South Africa," International Journal of Tuberculosis and Lung Disease, vol. 5, no. 7, pp. 619-627, 2001.

[129] E. R. Wandwalo and O. Mørkve, "Delay in tuberculosis casefinding and treatment in Mwanza, Tanzania," International Journal of Tuberculosis and Lung Disease, vol. 4, no. 2, pp. 133$138,2000$.

[130] S. Asch, B. Leake, R. Anderson, and L. Gelberg, "Why do symptomatic patients delay obtaining care for tuberculosis?" The American Journal of Respiratory and Critical Care Medicine, vol. 157, no. 4, pp. 1244-1248, 1998.
[131] S. D. Lawn, B. Afful, and J. W. Acheampong, "Pulmonary tuberculosis: diagnostic delay in Ghanaian adults," International Journal of Tuberculosis and Lung Disease, vol. 2, no. 8, pp. 635640, 1998.

[132] S. Enkhbat, M. Toyota, N. Yasuda, and H. Ohara, "Differing influence on delays in the case-finding process for tuberculosis between general physicians and specialists in mongolia," Journal of Epidemiology, vol. 7, no. 2, pp. 93-98, 1997.

[133] T. Mori, T. Shimao, B. W. Jin, and S. J. Kim, "Analysis of casefinding process of tuberculosis in Korea," Tubercle and Lung Disease, vol. 73, no. 4, pp. 225-231, 1992.

[134] F. Yan, R. Thomson, S. L. Tang et al., "Multiple perspectives on diagnosis delay for tuberculosis from key stakeholders in poor rural China: case study in four provinces," Health Policy, vol. 82, no. 2, pp. 186-199, 2007.

[135] M. Díez, M. J. Bleda, J. Alcaide et al., "Determinants of health system delay among confirmed tuberculosis cases in Spain," European Journal of Public Health, vol. 15, no. 4, pp. 343-349, 2005.

[136] N. H. Long, V. K. Diwan, and A. Winkvist, "Difference in symptoms suggesting pulmonary tuberculosis among men and women," Journal of Clinical Epidemiology, vol. 55, no. 2, pp. 115120, 2002.

[137] T. L. Creek, S. Lockman, T. A. Kenyon et al., "Completeness and timeliness of treatment initiation after laboratory diagnosis of tuberculosis in Gaborone, Botswana," International Journal of Tuberculosis and Lung Disease, vol. 4, no. 10, pp. 956-961, 2000.

[138] L. Pehme, K. Rahu, M. Rahu, and A. Altraja, "Factors related to health system delays in the diagnosis of pulmonary tuberculosis in Estonia," International Journal of Tuberculosis and Lung Disease, vol. 11, no. 3, pp. 275-281, 2007.

[139] L. F. Sherman, P. I. Fujiwara, S. V. Cook, L. B. Bazerman, and T. R. Frieden, "Patient and health care system delays in the diagnosis and treatment of tuberculosis," International Journal of Tuberculosis and Lung Disease, vol. 3, no. 12, pp. 1088-1095, 1999.

[140] C. E. French, M. E. Kruijshaar, J. A. Jones, and I. Abubakar, "The influence of socio-economic deprivation on tuberculosis treatment delays in England, 2000-2005," Epidemiology and Infection, vol. 137, no. 4, pp. 591-596, 2009.

[141] A. Bassili, A. Seita, S. Baghdadi et al., "Diagnostic and treatment delay in tuberculosis in 7 countries of the Eastern Mediterranean Region," Infectious Diseases in Clinical Practice, vol. 16, no. 1, pp. 23-35, 2008.

[142] G. D. Gosoniu, S. Ganapathy, J. Kemp et al., "Gender and sociocultural determinants of delay to diagnosis of TB in Bangladesh, India and Malawi," International Journal of Tuberculosis and Lung Disease, vol. 12, no. 7, pp. 848-855, 2008.

[143] D. M. Needham, S. D. Foster, G. Tomlinson, and P. GodfreyFaussett, "Socio-economic, gender and health services factors affecting diagnostic delay for tuberculosis patients in urban Zambia," Tropical Medicine and International Health, vol. 6, no. 4, pp. 256-259, 2001.

[144] Y. Mahendradhata, B. M. Syahrizal, and A. Utarini, "Delayed treatment of tuberculosis patients in rural areas of Yogyakarta province, Indonesia," BMC Public Health, vol. 8, article 393, 2008.

[145] S. Saly, I. Onozaki, and N. Ishikawa, "Decentralized dots shortens delay to TB treatment significantly in Cambodia," Kekkaku, vol. 81, no. 7, pp. 467-474, 2006.

[146] K. Sarmiento, Y. Hirsch-Moverman, P. W. Colson, and W. ElSadr, "Help-seeking behavior of marginalized groups: a study 
of TB patients in Harlem, New York," International Journal of Tuberculosis and Lung Disease, vol. 10, no. 10, pp. 1140-1145, 2006.

[147] M. A. P. S. dos Santos, M. F. P. M. Albuquerque, R. A. A. Ximenes et al., "Risk factors for treatment delay in pulmonary tuberculosis in Recife, Brazil," BMC Public Health, vol. 5, article 25, 2005.

[148] J. P. Vandenbroucke, E. von Elm, D. G. Altman et al., "Strengthening the reporting of observational studies in epidemiology (STROBE): explanation and elaboration," PLoS Medicine, vol. 4, no. 10, pp. 1628-1654, 2007.

[149] M. K. Campbell, D. R. Elbourne, and D. G. Altman, "CONSORT statement: extension to cluster randomised trials," The British Medical Journal, vol. 328, no. 7441, pp. 702-708, 2004.

[150] M. Zwarenstein, S. Treweek, J. J. Gagnier et al., "Improving the reporting of pragmatic trials: an extension of the CONSORT statement," The British Medical Journal, vol. 337, Article ID a2390, 2008.

[151] D. Somma, B. E. Thomas, F. Karim et al., "Gender and sociocultural determinants of TB-related stigma in Bangladesh, India, Malawi and Colombia," International Journal of Tuberculosis and Lung Disease, vol. 12, no. 7, pp. 856-866, 2008.

[152] E. L. Corbett, T. Bandason, T. Duong et al., "Comparison of two active case-finding strategies for community-based diagnosis of symptomatic smear-positive tuberculosis and control of infectious tuberculosis in Harare, Zimbabwe (DETECTB): a cluster-randomised trial," The Lancet, vol. 376, no. 9748, pp. 1244-1253, 2010.

[153] A. C. Miller, J. E. Golub, S. C. Cavalcante et al., "Controlled trial of active tuberculosis case finding in a Brazilian favela," International Journal of Tuberculosis and Lung Disease, vol. 14, no. 6, pp. 720-726, 2010.

[154] D. M. Tuller, D. R. Bangsberg, J. Senkungu, N. C. Ware, N. Emenyonu, and S. D. Weiser, "Transportation costs impede sustained adherence and access to HAART in a clinic population in Southwestern Uganda: a qualitative study," AIDS and Behavior, vol. 14, no. 4, pp. 778-784, 2010.

[155] A. P. Hardon, D. Akurut, C. Comoro et al., "Hunger, waiting time and transport costs: time to confront challenges to ART adherence in Africa," AIDS Care-Psychological and SocioMedical Aspects of AIDS/HIV, vol. 19, no. 5, pp. 658-665, 2007.

[156] M. Lubega, X. Nsabagasani, N. M. Tumwesigye et al., "Policy and practice, lost in transition: reasons for high drop-out from pre-antiretroviral care in a resource-poor setting of Eastern Uganda," Health Policy, vol. 95, no. 2-3, pp. 153-158, 2010.

[157] R. Levine, A. Glassman, and M. Schneidman, La Salud de la Mujer en América Latina y el Caribe, Inter-American Development Bank, Washington, DC, USA, 2001.

[158] S. S. Gopalan and V. Durairaj, "Addressing women's non-maternal healthcare financing in developing countries: what can we learn from the experiences of rural indian women?" PLOS ONE, vol. 7, no. 1, Article ID e29936, 2012.

[159] I. M. Kigozi, L. M. Dobkin, J. N. Martin et al., "Late-disease stage at presentation to an HIV clinic in the era of free antiretroviral therapy in Sub-Saharan Africa," Journal of Acquired Immune Deficiency Syndromes, vol. 52, no. 2, pp. 280-289, 2009.

[160] M. Charurat, M. Oyegunle, R. Benjamin et al., "Patient retention and adherence to antiretrovirals in a large antiretroviral therapy program in Nigeria: a longitudinal analysis for risk factors," PLoS ONE, vol. 5, no. 5, Article ID e10584, 2010.

[161] M. Chileshe and V. A. Bond, "Barriers and outcomes: TB patients co-infected with HIV accessing antiretroviral therapy in rural Zambia," AIDS Care-Psychological and Socio-Medical Aspects of AIDS/HIV, vol. 22, supplement 1, pp. 51-59, 2010.

[162] C. Jasseron, L. Mandelbrot, C. Dollfus et al., "Non-disclosure of a pregnant woman's HIV status to her partner is associated with non-optimal prevention of mother-to-child transmission," AIDS and Behavior, vol. 17, no. 2, pp. 488-497, 2013.

[163] J. Ostermann, E. A. Reddy, M. M. Shorter et al., "Who tests, who doesn't, and why? Uptake of mobile HIV counseling and testing in the kilimanjaro region of Tanzania," PLoS ONE, vol. 6, no. 1, Article ID e16488, 2011.

[164] S. V. Eastwood and P. C. Hill, "A gender-focused qualitative study of barriers to accessing tuberculosis treatment in the Gambia, West Africa," International Journal of Tuberculosis and Lung Disease, vol. 8, no. 1, pp. 70-75, 2004.

[165] R. Liefooghe, N. Michiels, S. Habib, M. B. Moran, and A. de Muynck, "Perception and social consequences of tuberculosis: a focus group study of tuberculosis patients in Sialkot, Pakistan," Social Science and Medicine, vol. 41, no. 12, pp. 1685-1692, 1995.

[166] R. Liefooghe, J. B. Baliddawa, E. M. Kipruto, C. Vermeire, and A. O. de Munynck, "From their own perspective. A Kenyan community's perception of tuberculosis," Tropical Medicine and International Health, vol. 2, no. 8, pp. 809-821, 1997.

[167] A. Daftary, "HIV and tuberculosis: the construction and management of double stigma," Social Science and Medicine, vol. 74, no. 10, pp. 1512-1519, 2012.

[168] S. McTavish, S. Moore, S. Harper, and J. Lynch, "National female literacy, individual socio-economic status, and maternal health care use in sub-Saharan Africa," Social Science and Medicine, vol. 71, no. 11, pp. 1958-1963, 2010.

[169] P. K. Nirmalan, A. Padmavathi, and R. D. Thulasiraj, "Sex inequalities in cataract blindness burden and surgical services in south India," The British Journal of Ophthalmology, vol. 87, no. 7, pp. 847-849, 2003.

[170] L. Gilson, J. Doherty, R. Loewenson, and V. Francis, Challenging Inequity Through Health Systems, WHO Commission on the Social Determinants of Health, 2007.

[171] G. Sen, P. Östlin, and A. George, Unequal, Unfair, Ineffective and Inefficient-Gender InequIty in Health: Why It Exists and How We Can Change It, WHO Commission on Social Determinants of Health, 2007.

[172] V. K. Diwan and A. Thorson, "Sex, gender, and tuberculosis," The Lancet, vol. 353, no. 9157, pp. 1000-1001, 1999.

[173] H. Getahun, D. Sculier, C. Sismanidis, M. Grzemska, and M. Raviglione, "Prevention, diagnosis, and treatment of tuberculosis in children and mothers: evidence for action for maternal, neonatal, and child health services," Journal of Infectious Diseases, vol. 205, supplement 2, pp. S216-S227, 2012.

[174] L. Nieuwenhoven and I. Klinge, "Scientific excellence in applying sex- and gender-sensitive methods in biomedical and health research," Journal of Women's Health, vol. 19, no. 2, pp. 313-321, 2010.

[175] “Taking sex into account in medicine," The Lancet, vol. 378, no. 9806, p. 1826, 2011.

[176] "Manifesto for integrated action on the gender dimension in research and innovation," http://www.gender-summit.eu/index .php?option $=$ com_content\&view=article\&id=278\&Itemid $=42$.

[177] Gendered Innovations in Science, Health \& Medicine, and Engineering, 2011, http://genderedinnovations.eu.

[178] WHO, Strategy for Integrating Gender Analysis and Actions into the Work of WHO, WHO, 2009. 


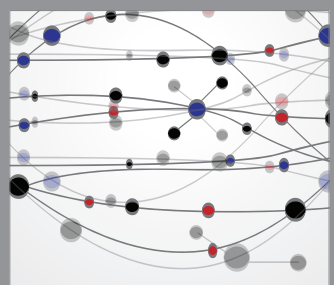

The Scientific World Journal
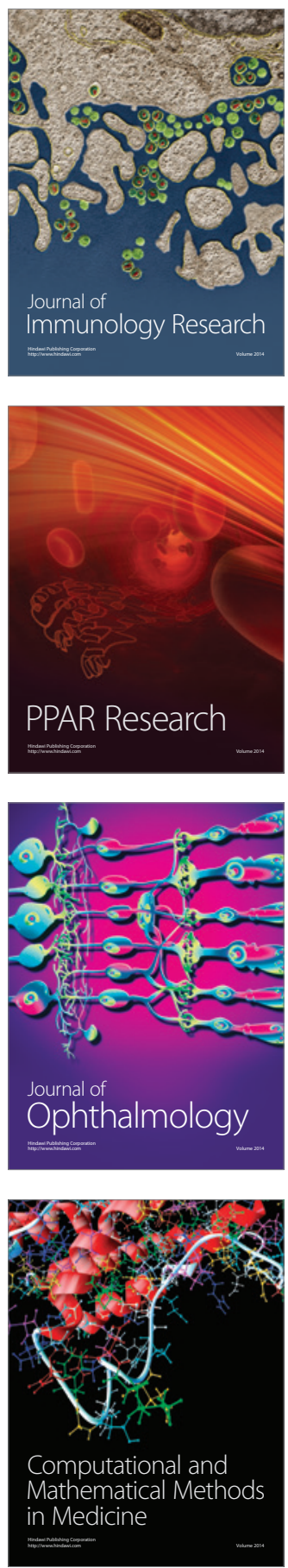

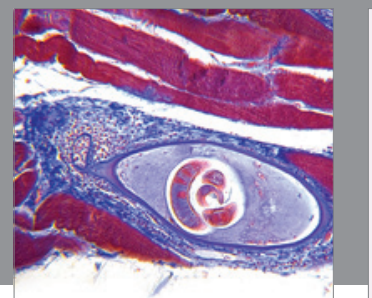

Gastroenterology

Research and Practice
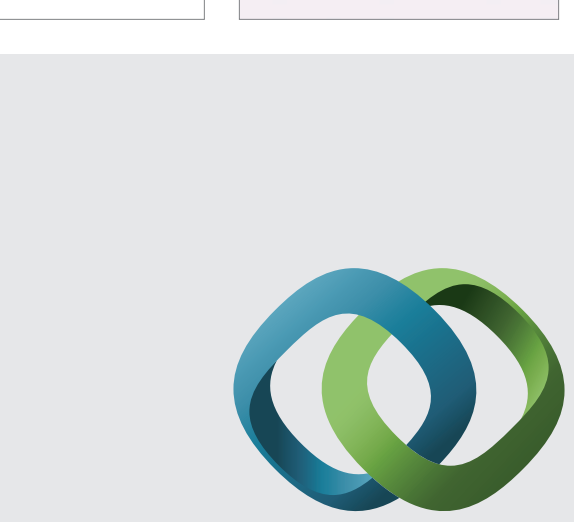

\section{Hindawi}

Submit your manuscripts at

http://www.hindawi.com
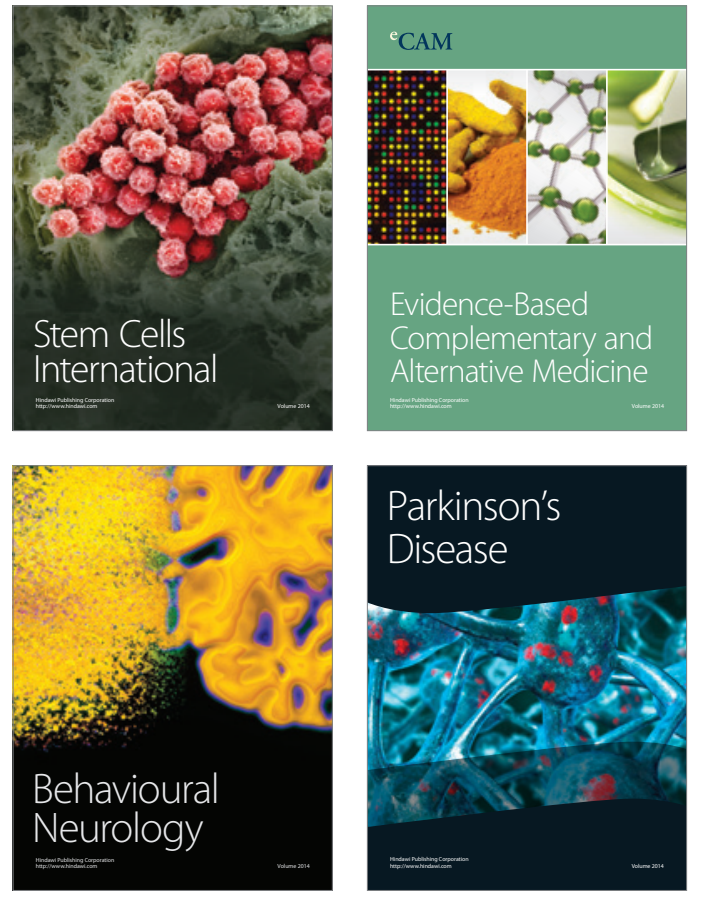
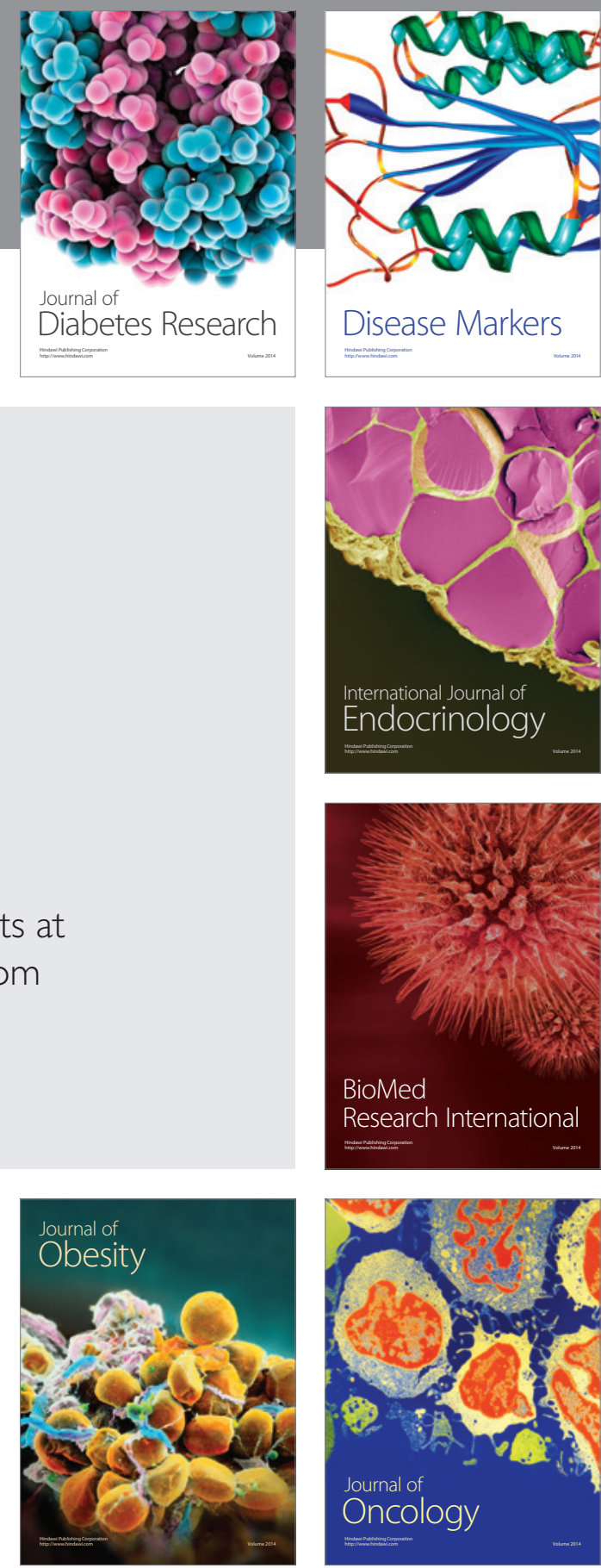

Disease Markers
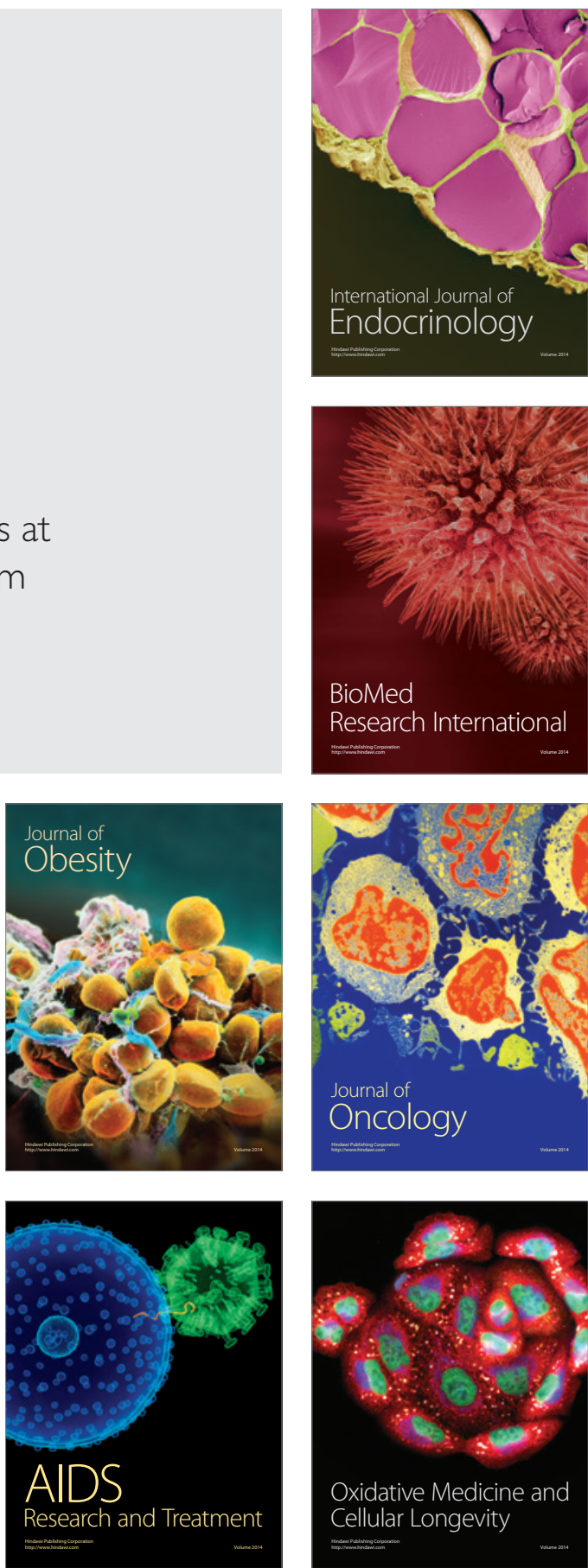